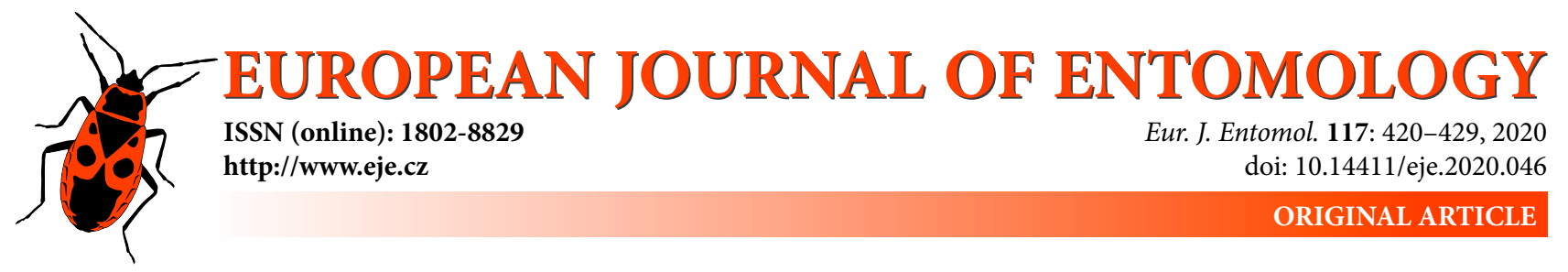

\title{
Contribution of a DNA barcode to an assessment of the specificity of ant taxa (Hymenoptera: Formicidae) on Corsica
}

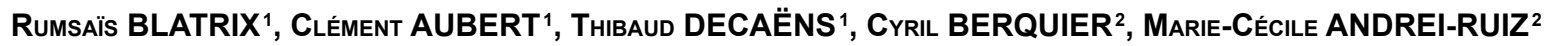 \\ and CHRISTOPHE GALKOWSKI ${ }^{3}$ \\ ${ }^{1}$ CEFE, Univ Montpellier, CNRS, EPHE, IRD, Univ Paul Valéry Montpellier 3, 1919 route de Mende, 34293 Montpellier, France; \\ e-mails: rumsais.blatrix@cefe.cnrs.fr, Clement.aubert34@hotmail.fr, thibaud.decaens@cefe.cnrs.fr \\ ${ }^{2}$ Conservatoire des Insectes de Corse, Office de l'Environnement de la Corse (OEC-OCIC), 14 Avenue Jean Nicoli, 20250 \\ Corte, France; e-mails: Cyril.Berquier@oec.fr, Marie-Cecile.Ruiz@oec.fr \\ 3104 route de Mounic, 33160 Saint Aubin de Médoc, France; email: chris.gal@wanadoo.fr
}

Key words. Hymenoptera, Formicidae, ants, Corsica, Mediterranean islands, COI, barcode, integrative taxonomy, synonymy

\begin{abstract}
We used the COI marker, the most popular DNA barcode for the animal kingdom, to assess the taxonomic status of Corsican populations of eight groups of species of ants that occur both on Corsica and the European mainland. (i) In two groups, we detected no genetic differentiation between Corsica and the continent. Absence of differentiation across varieties of Aphaenogaster spinosa within Corsica confirm current synonymies. (ii) In four groups, we detected strong genetic differentiation between Corsica and the continent, confirming recent taxonomic studies based on morphology for three of these groups. For the fourth group, we propose that the status of Corsican populations be raised from sub-species to species: Temnothorax cordieri stat. rev. (iii) In one group, the genetic differentiation and morphological differences do not support splitting and as a consequence we propose to accept the previous synonymy Temnothorax tuberum = Temnothorax melanocephalus. (iv) In Myrmica scabrinodis and Myrmica spinosior, COI sequence information is largely inconsistent with morphology and geography, not only on Corsica but also on the mainland, and should not be used to support taxonomic decisions. Although the use of COI has drawbacks, it is globally consistent with morphology and can be used to complement morphological ant taxonomy. We provide an updated checklist of ants of Corsica.
\end{abstract}

ZooBank Article Registration: http://zoobank.org/urn:Isid:zoobank.org:pub:6893D359-C223-490B-BFE7-05558B16426C

\section{INTRODUCTION}

Spatial isolation, drift due to founder effect and natural selection result in faster speciation on islands than on continents (Barton, 1996). However, deciding whether or not island populations should be treated as species is difficult because speciation is an ongoing process of which we only have a snapshot. An increasing number of methods are becoming available for delineating species and a reasonable approach is to rely as much as possible on various independent sources of information (Dayrat, 2005; Will et al., 2005).

The Mediterranean basin is a biodiversity hotspot for conservation (Myers et al., 2000). Islands (the Tyrrhenian islands in particular, such as Corsica) contribute to this (Medail \& Quezel, 1997) as they host a high proportion of endemic taxa (e.g. Grill et al., 2007). Corsica is one of the islands on which the biodiversity is well studied, but there is a lack of knowledge in this respect on the invertebrates. For instance, although there are at least 25 publications published from 1901 to 2016 on the ant fauna of Corsica, several additional species of ants were recorded recently (Blatrix et al., 2017; Colindre \& Galkowski, 2019).

Four valid species and two subspecies or varieties of ants are currently considered to be endemic to Corsica (Blatrix et al., 2018). Until now, only information on morphology was used in taxonomic studies on Corsican ants. As a first step in determining the potential of DNA barcode sequences as an additional source of information for studying the taxonomy of Corsican ants, we sequenced the mitochondrial cytochrome c oxidase subunit I (COI) gene for eight species or species groups that occur both on Corsica and the European mainland. We choose purposely species or species groups that were expected to differ. Although the use of DNA barcodes in taxonomy is criticized, it can help delineate species if used to complement other sources of information (Hebert \& Gregory, 2005). In addition, COI is the DNA fragment most frequently sequenced in insects for comparing related species and that of insects is easily amplified using universal primers. 
Below we describe the eight focal species or groups of species and indicate our expectation regarding sequence divergence based on what we know about their biology and morphology.

1. Camponotus aethiops (Latreille, 1798) is widespread and common in the northern half of the Mediterranean area. It varies little in morphology throughout its range. We do not expect the Corsican population to be different. This species is the host of a social parasite, the ant Camponotus universitatis Forel, 1890. Two forms of $C$. universitatis are recognized: one is found exclusively in nests of Camponotus aethiops and the other exclusively in nests of Camponotus pilicornis (Roger, 1859). This second form awaits formal description and is not known on Corsica. We will consider only the first form. As it is considered rare, we expect it to be scarce and thus could be subject to strong genetic drift on islands. Some degree of sequence divergence might thus be expected between Corsican and continental populations.

The Western Palaearctic region hosts many species of Lasius, which are difficult to identify as they vary very little in their morphology. New species are being described regularly (e.g. Talavera et al., 2015; Seifert \& Galkowski, 2016). We focused on two species that occur on Corsica: Lasius grandis Forel, 1909 and Lasius casevitzi Seifert \& Galkowski, 2016.

2. Lasius emarginatus (Olivier, 1792) is widespread and common in Europe, mostly in the South. It varies markedly throughout its range. This species is relatively common on Corsica, but Corsican populations were recently attributed to Lasius grandis (Seifert, 2020). Corsican populations are labelled Lasius COR sp1 in the atlas of ants on Corsica (Blatrix et al., 2018) and we will use this code in the present study in order to indicate its ambiguous identity. Lasius COR sp1 has a colour pattern similar to that of Lasius emarginatus, which may explain why it is mistaken with it in previous studies on the Corsican myrmecofauna. Its morphometry, however, does not distinguish it from Lasius grandis (Seifert, 2020). We thus expect sequences of Corsican Lasius COR sp1 to be very different from those of continental Lasius emarginatus and differ little from those of continental L. grandis.

3. Lasius casevitzi was described in 2016 (Seifert \& Galkowski, 2016) from Corsica and before that the Corsican populations were considered to be Lasius paralienus Seifert, 1992. There are subtle but consistent morphological differences between these two species. Although at first it was thought to be a Corsican endemic, it has recently been found on mainland Italy, Sicily and the Aeolian islands (Schär et al., 2020; Seifert, 2020) and appears to be a Tyrrhenian species. We expect a marked sequence difference between Lasius casevitzi on Corsica and L. paralienus on the continent, of the same order as among other species of Lasius.

4. Although Myrmica is an Holarctic genus whose species occur mostly in areas with temperate and humid climates, several species occur in the Mediterranean region. The genus is morphologically very homogeneous and spe- cies identification is difficult. Only two species of $M y r-$ mica are currently known on Corsica. Myrmica spinosior Santschi, 1931 is restricted to the Mediterranean part of Western Europe, and is common and widespread on Corsica. Myrmica scabrinodis Nylander, 1846 is widespread in Europe and Western Asia, but very rare on Corsica. Following the species group concept of Radchenko \& Elmes (2010), both species belong to the scabrinodis-group, within which Myrmica spinosior belongs to the sabuleti-complex and Myrmica scabrinodis to the scabrinodis-complex. Corsican populations of these two species differ slightly morphologically from their respective continental counterparts, but not enough to consider them as distinct species. The workers of the two species on Corsica are difficult to differentiate, but males clearly differ. We expect some sequence divergence between Corsica and the continent for these two species, but more so for Myrmica scabrinodis because the size of its Corsican population is much smaller than that of $M$. spinosior. Two highly differentiated phylogenetic clades of $M$. scabrinodis were recently identified on mainland Europe (Ebsen et al., 2019). Is there a similar pattern on Corsica and/or for other species of Myrmica?

5. Temnothorax unifasciatus (Latreille, 1798) is a widespread European species, very common in a wide range of habitats. The Corsican populations of Temnothorax unifasciatus are morphologically distinct from the continental ones and are designated as a subspecies T. u. cordieri (Bondroit, 1918). We thus expect strong sequence divergence between Corsica and the continent.

6. Temnothorax tuberum (Fabricius, 1775) is a widespread European species restricted to boreo-alpine environments. The Corsican population was first described as a distinct species, Leptothorax melanocephalus Emery, 1870. It was later synonymized with Temnothorax tuberum (Casevitz-Weulersse, 1990), and recently revived from synonymy, based on specimens from Ukraine (Radchenko, 2016). We expect marked sequence divergence between the Corsican Temnothorax melanocephalus and the continental $T$. tuberum because of the large distance between these populations.

7. Temnothorax mediterraneus Ward, Brady, Fischer \& Schultz, 2014 is restricted to Corsica, Sardinia and Sicily. Continental populations that were previously attributed to this species have recently been described as a distinct species, Temnothorax continentalis Galkowski \& Cagniant, 2017 (Galkowski \& Cagniant, 2017). These two species are clearly distinct morphologically and, therefore, it is likely that the sequences of Temnothorax mediterraneus and continental $T$. continentalis will be markedly different.

8. Aphaenogaster spinosa Emery, 1878 is restricted to Corsica, Sardinia and the North-West coast of Italy. As queens do not swarm but found new colonies by budding, we may expect some degree of genetic differentiation of the mitochondrial markers between island and continental populations. The taxa Aphaenogaster testaceopilosa var. nitida Krausse, 1912 and Aphaenogaster corsica CasevitzWeulersse, 2010 are now considered junior synonyms of A. spinosa (Baroni-Urbani, 1971a; Boer, 2013). Both, in 
addition to the nominal form, occur on Corsica. Molecular markers are expected to help in the evaluation of the taxonomic relevance of the morphological variation in this species.

\section{MATERIAL AND METHODS}

New DNA sequences for part of the gene coding for the cytochrome c oxidase subunit I (COI, $658 \mathrm{bp}$ ) were obtained either within the framework of the International Barcode of Life project (iBOL) or ANTAGENE (La Tour de Salvagny, France) or the Centre for Evolutionary and Functional Ecology (CEFE) in Montpellier, France. In the two latter cases, each specimen was used entirely for DNA extraction, whereas in the former case, only one leg was used and vouchers were stored at the CEFE. After DNA extraction, the COI fragments were amplified using a polymerase chain reaction (PCR) using the primer pairs LepF1: 5'-ATTCAACCAATCATAAAGATAT-3' and LepR1: 5'-TAAACTTCTGGATGTCCAAAAA-3' (Hebert et al., 2004). Sanger dideoxy sequencing of PCR amplicons was performed in both directions using the same primers as those used for the initial amplification. Sequences were edited using CodonCode Aligner (CodonCode Corporation, Dedham, MA, USA) and contigs were built from forward and reverse sequences generated for each gene. Conflicting base calls were coded using the ambiguity code. Sequences were aligned with Muscle (Edgar, 2004). Alignments were inspected visually and edited manually using MEsQUITE v. 3.31 (Maddison \& Maddison, 2017) when they could be improved. Genetic distances were estimated in Mesquite using the Kimura 2-parameter model (K2p).

A partition scheme was defined using PartitionFinder (Lanfear et al., 2016) for each phylogenetic analysis, using the Akaike Information Criteria for nucleotide substitution model selection. Prior data blocks were defined by codon position. Phylogenetic reconstructions were performed using Bayesian inference with MrBayes v. 3.2.6 (Ronquist et al., 2012). Two analyses of four chains were run for 1,000,000 generations $(10,000,000$ for $M y r-$ mica) and trees were sampled every 500 generations with $25 \%$ burn-in samples discarded for each run. Phylogenetic trees were rooted arbitrarily (by default the first taxon in the matrix) and rerooted manually using several species as outgroups. Our choices for outgroups were guided either by recent phylogenetic studies (Maruyama et al., 2008; Jansen et al., 2010) or by morphologybased assumptions of species relationships within genera (for Camponotus and Temnothorax).

Quantitative morphological comparisons of continental and Corsican populations of Temnothorax unifasciatus were based on maximum head width (HW, including the eyes) and length of the propodeal spine (SPST: distance between the centre of the propodeal stigma and tip of the propodeal spine in lateral view) for 30 continental and 28 Corsican workers, and HW for 16 continental and 10 Corsican queens. These characters were chosen because they are considered to be the most discriminant between continental and Corsican populations (Bondroit, 1918; Plateaux \& Cagniant, 2012).

\section{RESULTS}

For this study, 227 new COI sequences were generated (108 by iBOL, 107 by ANTAGENE and 12 by the CEFE), with GenBank accession numbers MH138351 to MH138393, MH138395 to MH138397, MH138399 to MH138474, MH138476 to MH138479 and MN731371 to MN731477 (Table S1). Sequences are also publicly available on the dataset "DS-ANTCOR - Specificity of the ant fauna of Corsica" of the BOLD - Barcode of Life Data Systems (Doi: dx.doi.org/10.5883/DS-ANTCOR). This dataset includes 658 characters.

1. Camponotus aethiops and C. universitatis (Fig. 1). These two species form two well supported clades with a $\mathrm{K} 2 \mathrm{p}$ genetic distance of $9.4 \%$. For both species, the genetic distance between Corsican and continental samples is lower than $0.2 \%$, indicating no detectable differentiation.

2. Lasius COR sp1 (Fig. 1). The clades composed of Lasius emarginatus (from France and Italy) and L. grandis are both well supported and clearly distinct from Corsican Lasius COR sp1. One sample of Lasius grandis from Saint-Gely-du-Fesc is within the clade of Lasius cinereus, but it is likely it was misidentified as workers of these two species are particularly difficult to distinguish in this region (pers. observ.). One Corsican sample, from Poggio-diVenaco, is closely related to Lasius emarginatus, but all the other Corsican samples form a well-supported clade that has a K2p genetic distance of $2.8 \%$ from $L$. emarginatus and $4.5 \%$ from L. grandis. Deep nodes have low support values.

3. Lasius paralienus (on the continent) and Lasius casevitzi (on Corsica) (Fig. 1). These two species form two well supported clades with a K2p genetic distance of $2.9 \%$.

4. Myrmica spinosior and Myrmica scabrinodis (Fig. 2). The sequences of these two species form four, well supported, major clades. Clade 1 contains only continental samples of M. scabrinodis (from France, Germany and Finland). Clade 2 is a mixture of continental and Corsican samples of $M$. scabrinodis and $M$. spinosior. Clade 3 is composed of continental samples of $M$. sabuleti and $M$. spinosior. Clade 4 is a mixture of Corsican samples of $M$. scabrinodis and $M$. spinosior. The $\mathrm{K} 2 \mathrm{p}$ genetic distance between $M$. spinosior and M. scabrinodis on the continent (in clades 3 and 1 ) is $2.2 \%$. The two clades containing Corsican samples (clades 2 and 4 ) have a K2p genetic distance of $3.5 \%$ and both are composed of a mixture of samples of M. spinosior and M. scabrinodis. Several samples do not fit in any of the four clades named above. For instance, one sample of M. scabrinodis from Italy (Tuscany) is very basal and seems closely related to Myrmica tulinae Elmes et al., 2002. Another one, from continental France, is closely related to Myrmica aloba Forel, 1909. In most cases we sequenced only one worker per colony, but for 35 colonies we sequenced two (or three) workers. In one case, the two workers are in distinct clades. Deep nodes have low support values, precluding any inference on the phylogenetic relationships between clades.

5. Temnothorax unifasciatus (Fig. 1). Propodeal spines of workers from Corsica are significantly longer than those of continental workers (SPST/HW mean $\pm \mathrm{sd}$, Temnothorax cordieri: $0.297 \pm 0.024$, T. unifasciatus: $0.260 \pm 0.023$, Mann-Whitney U-test: $\mathrm{U}=735, \mathrm{p}<10^{-5}$; Figs 3a, b, S1). Queens from Corsica are significantly smaller than those from the continent (HW mean $\pm \mathrm{sd}$, T. cordieri: $695 \pm 20$ $\mu \mathrm{m}$, T. unifasciatus: $741 \pm 19$, Mann-Whitney U-test: $\mathrm{U}=$ $8, \mathrm{p}<10^{-3}$; Fig. 3c). However, both morphological characters overlap (Fig. 3). Although it is reported that the work- 

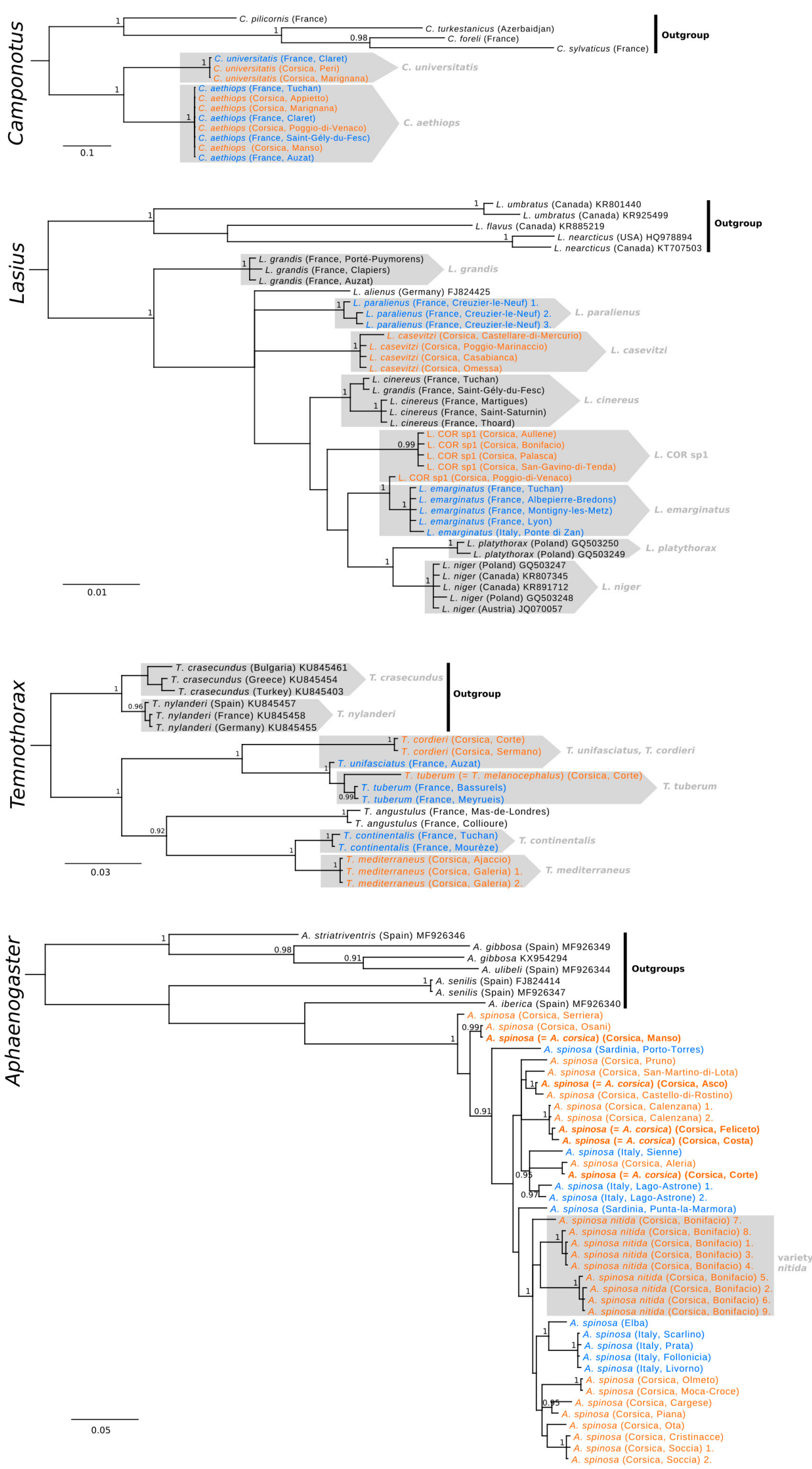

Fig. 1. Cytochrome $\mathrm{c}$ oxidase subunit I gene ( $\mathrm{COI}$ ) phylogenies based on a Bayesian approach. Labels in black, orange and blue are the non-focal taxa (including outgroups), Corsican and continental samples, respectively. For Aphaenogaster spinosa, labels in bold correspond to specimens that fit the description of Aphaenogaster corsica. Posterior probabilities above 0.90 are indicated. 


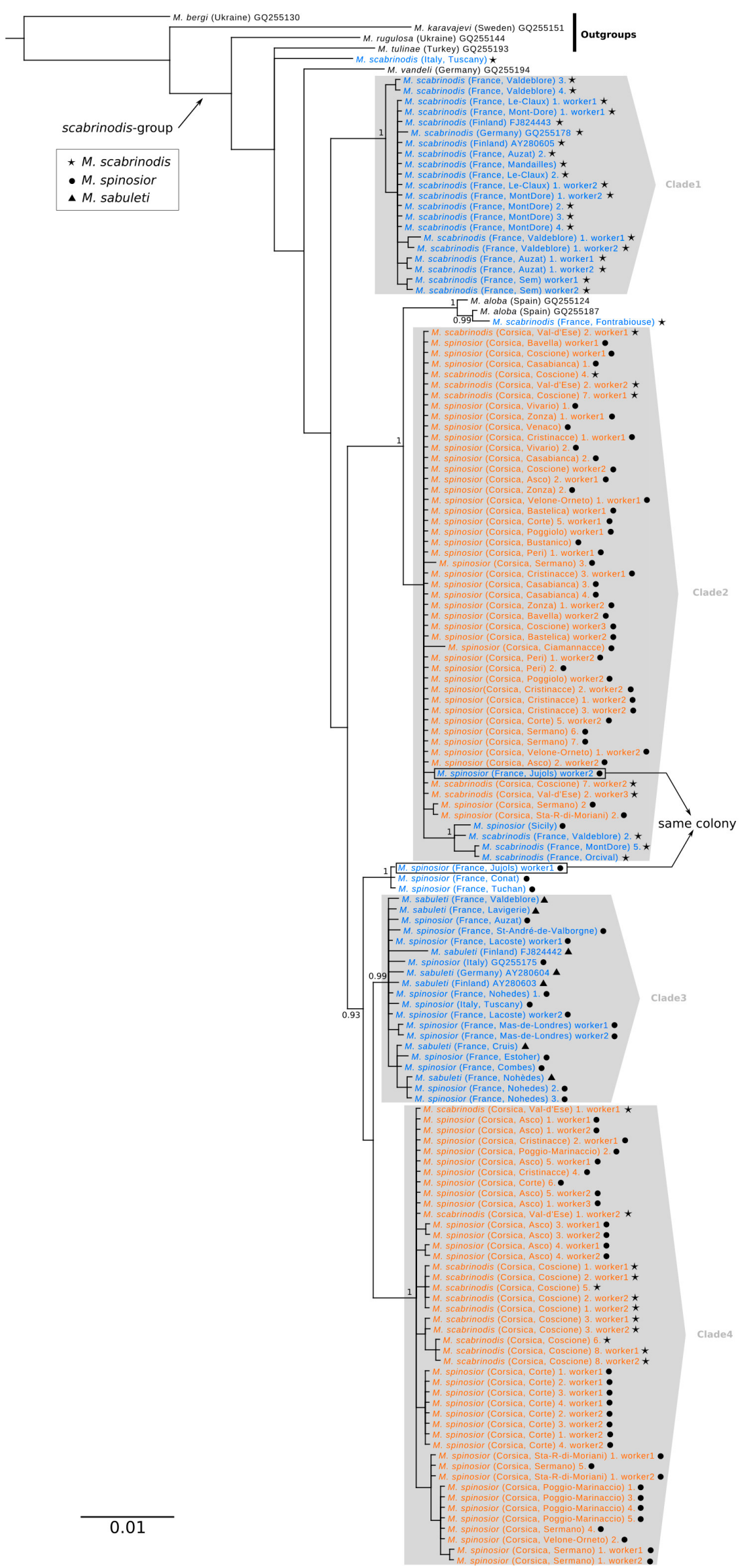

Fig. 2. Cytochrome c oxidase subunit I gene (COI) phylogenies of several species of Myrmica in the scabrinodis-group (in particular, $M$. scabrinodis, M. spinosior and M. sabuleti), based on a Bayesian approach. Labels in black, orange and blue are non-focal taxa (including outgroups), Corsican and continental samples, respectively. Posterior probabilities above 0.90 are indicated. 
(a) Workers

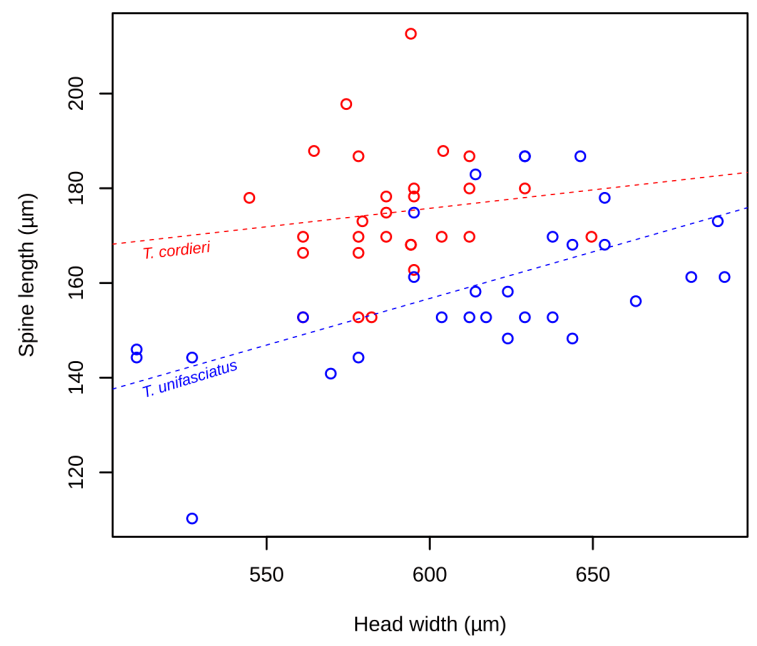

(b) Workers

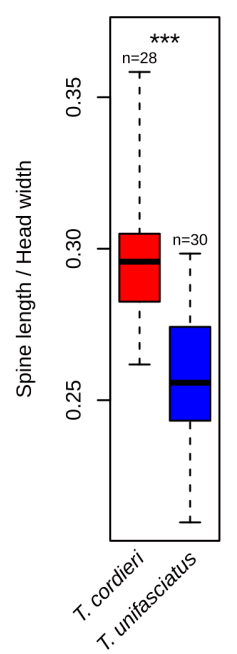

(c) Queens

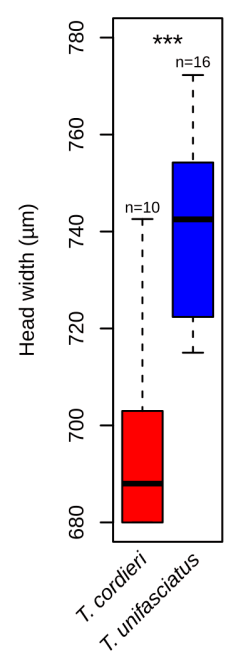

Fig. 3. Morphological comparison of Temnothorax unifasciatus (continent) (in blue) and Temnothorax cordieri (Corsica) (in red). (a) Length of propodeal spine as a function of head width (as of proxy of size) for workers. (b) Comparison of length of propodeal spine relative to head width of workers of the two species. (c) Comparison of head width (as a proxy of size) of queens of the two species. For (b) and (c), horizontal lines represent medians, boxes represent interquartile ranges and whiskers extend to the data extremes. ${ }^{* * *}-p<10^{-3}$.

ers differ in colour (Plateaux \& Cagniant, 2012), we do not find it sufficiently pronounced to consider this trait as a distinctive character (Fig. S1). The only colour difference that seems relevant is that the genae are darker than rest of the head in most specimens of $T$. cordieri, but only in a small proportion of the specimens of T. unifasciatus (Fig. $\mathrm{S} 1)$. Corsican and continental samples have a K2p genetic distance of $8.6 \%$ and do not form a monophyletic clade.

6. Temnothorax tuberum (on the continent) and T. melanocephalus (on Corsica) (Fig. 1). Corsican and continental samples have a K2p genetic distance of $2.7 \%$ and form a monophyletic clade.

7. Temnothorax continentalis (on the continent) and $T$. mediterraneus (on Corsica) (Fig. 1). These two species form two well supported clades with a K2p genetic distance of $3.9 \%$.

8. Aphaenogaster spinosa (Fig. 1). This species forms a well-supported monophyletic clade in which continental and island specimens are intermixed. Specimens attributed to Aphaenogaster corsica, now synonymized with $A$. spinosa (Boer, 2013), are scattered within this clade. Most specimens of the variety nitida form a monophyletic clade within A. spinosa, but it is poorly supported (Posterior probability $<0.6$ ). Corsican specimens of $A$. spinosa have an average $\mathrm{k} 2 \mathrm{p}$ genetic distance of $4.1 \%$.

\section{DISCUSSION}

The COI marker of Camponotus aethiops and its social parasite, $C$. universitatis differ greatly. However, there is no detectable differentiation between Corsican and continental samples. This result was expected for $C$. aethiops because there is no morphological differentiation between individuals from Corsica and the continent and this species is widespread and very common in the Mediterranean region. In contrast, individuals from Corsica and the continent of $C$. universitatis were considered likely to differ markedly because this species is rare and might be subject to population isolation. Either COI in the genus Camponotus varies very little, or C. universitatis is not rare, but merely undetected throughout most of its distribution. Similarly, Schär et al. (2020) found little intraspecific variation in COI among mainland Italy, Sicily and the Aeolian islands for various species of Camponotus. As they point out, in general the subfamily Formicinae might show lower intraspecific genetic variability than the subfamily Myrmicinae.

In three of the eight cases studied, strong COI differentiation between Corsica and the continent confirm observed morphological differences and the assignment of Corsican and continental populations to different species:

(i) Corsican Lasius that were originally identified as $L$. paralienus were recently described as a distinct species, $L$. casevitzi (Seifert \& Galkowski, 2016).

(ii) Continental Temnothorax that were originally identified as T. mediterraneus were recently described as Temnothorax continentalis (Galkowski \& Cagniant, 2017), a species distinct from Corsican and Sardinian T. mediterraneus. T. mediterraneus was originally described from Sardinia.

(iii) Corsican populations of Temnothorax unifasciatus were attributed to the subspecies cordieri, based on morphological characters (Plateaux \& Cagniant, 2012). Although the workers in Corsican populations have significantly longer propodeal spines and darker genae and the queens are smaller than those in continental populations, measurement ranges of the two forms overlap and no fully diagnostic character was found. However, COI differentiation between Corsica and the continent is very high (8.6\%). For comparison, Temnothorax nylanderi and $T$. crasecundus, two closely related but clearly separated species (Csosz et al., 2015), have a genetic distance of 3.1\%. Interbreeding between Corsican and continental popula- 
tions of T. unifasciatus under laboratory conditions was used to justify conspecificity (Casevitz-Weulersse, 1990), but reproductive isolation must have been effective for a long time given the high COI differentiation. Thus, we propose to revive the species status of Corsican populations: Temnothorax cordieri (Bondroit, 1918) stat. rev. Morphologically, T. cordieri is most similar to T. unifasciatus, from which it cannot always be confidently distinguished. It can be distinguished from other species of Temnothorax using the same characters as for T. unifasciatus. In particular, in T. cordieri, the transverse band on the posterior third of the tergite of the first gaster is dark brown to black, well demarcated and of constant width; the three most apical segments of the antenna (antennal club) are conspicuously darkened; and the top of the petiole is somewhat rounded. In contrast, the band narrows medially in T. albipennis (Curtis, 1854). In T. luteus (Forel, 1874), the band is only slightly darker than the rest of the gaster and the antennal club is usually the same colour as the rest of the antenna (at most, the most apical segment can be slightly darker). In $T$. aveli (Bondroit, 1918), anterior and posterior faces of the petiole meet at a right angle.

Lasius COR sp1 was first attributed to L. emarginatus, mostly based on colouration and hairiness (Casevitz-Weulersse, 1990), and has recently been attributed to L. grandis based on morphometrics (Seifert, 2020). Our study indicates it is a distinct species. The genetic distance between Lasius COR sp1 and both L. emarginatus and L. grandis is greater than the distance between the two sister species, Lasius niger (Linnaeus, 1758) and L. platythorax Seifert, 1991 (1.7\%). The genetic distance between Lasius COR sp1 and L. grandis $(4.5 \%)$ is clearly greater than intraspecific distances in this genus. Thus, our results are in conflict with the current taxonomic treatment of this Corsican taxon. Interestingly, Schär et al. (2020) found strong genetic differentiation between samples of Lasius emarginatus from Sicily and continental Italy. A regional investigation of these taxa of Lasius at the scale of the North-western Mediterranean area should be undertaken to define the taxonomic status of the Tyrrhenian populations. Deep nodes in our COI-based Lasius phylogeny are poorly supported, preventing any interpretation of the phylogenetic relationships between these species. In particular, it is unclear whether Lasius COR sp1 is a sister to L. emarginatus or to other continental species such as $L$. cinereus and $L$. grandis. Additional markers should be used to address this issue.

Temnothorax melanocephalus, described from Corsica, is sometimes considered as a species distinct from T. tuberum and sometimes a subspecies or synonym of it. In the former case, this is either based on only the type specimen of T. melanocephalus (e.g. Bondroit, 1920) or the authors follow Bondroit (1920) without any justification (e.g. Baroni Urbani, 1971b; Collingwood, 1978). The recent decision of Radchenko (2016) to revive this taxon from synonymy also lacks any justification or explanation. Ant specialists sometimes claim that Temnothorax tuberum shows slight morphological variation across mountain ranges (pers. comm.), which may explain this taxonomic instability. Such putative local variation, if any, may result from isolation by distance. However, our own investigation of samples from more than 20 nests on Corsica did not reveal any consistent combination of characters that differed from continental samples from the Alps, Massif Central and Pyrenees. In addition, using the most recent key to European Temnothorax (i.e. Seifert, 2018), Corsican samples keyed out unambiguously as T. tuberum. As we did not investigate samples from Sweden, the type locality of T. tuberum, we cannot rule out that populations from southern Europe (Corsican and continental) could belong to a taxon distinct from the nominotypical T. tuberum. Continental and Corsican populations are separated not only by the sea, but also by the distance between mountain tops. The genetic differentiation between Corsican and continental samples is $2.7 \%$, a value lying in the middle of the range of cut-off values used to consider clades of ants as distinct species. For instance, this value is lower than the distance between the two closely related species Temnothorax nylanderi and T. crasecundus. We consider this genetic distance is the result only of isolation by distance and does not reflect reproductive incompatibility. Given the distribution of Temnothorax tuberum, COI sequences and lack of conspicuous morphological differentiation, we support conspecificity rather than the splitting of Corsican and continental populations. In the case that their morphology is shown to be different on each mountain range then this would probably require splitting the taxon into as many species as there are mountain ranges. In the absence of strong arguments in favour of such a split (morphological variation not yet demonstrated), and in the absence of any justification of the decision of Radchenko (2016) to revive Temnothorax melanocephalus from synonymy, it is wiser to consider T. tuberum and its Corsican variety as a single species. Here we therefore accept the synonymy Temnothorax tuberum = Temnothorax melanocephalus proposed by Casevitz-Weulersse (1990).

We found that the morphological classification and COI sequence information are highly inconsistent in the Myrmica scabrinodis-group (which includes the focal species of this study, M. scabrinodis and M. spinosior). Recently, Ebsen et al. (2019) report that two major mitochondrial lineages of M. scabrinodis occur on mainland Europe. As we sequenced a different fragment of COI it is not possible to relate the clades we identified with theirs. Nevertheless, we observed a similar pattern: Myrmica scabrinodis samples were distributed in at least three clades. In addition, we found a similar pattern for M. spinosior, which was distributed in three clades. Surprisingly, the two clades on Corsica are both a mixture of M. spinosior and M. scabrinodis, although these two species belong to distinct species complexes (according to the concepts of Radchenko \& Elmes, 2010). One of these Corsican clades also contained continental samples of both species. These two clades even co-occurred at the same locations (i.e. Val d'Ese, Plateau de Coscione, Asco, Corte, Sermano), showing that genetic differentiation of COI is not only inconsistent with species 
identity but also with spatial distribution. It is unlikely that the discrepancy between morphology and sequence information could result from some clades containing nuclear copies of mitochondrial genes (numts), because we could not detect any stop codon in the sequences and the Corsican clades are not so strongly differentiated. Strong differentiation is expected when selective pressure on coding genes is released, as is the case for numts. Ebsen et al. (2019) propose that the two major lineages of Myrmica scabrinodis on mainland Europe are most likely cryptic species. Our results suggest that the explanation of the discrepancy between morphology and COI sequence information is more complex (although we have no robust alternative scenario to propose). First, in one case, two workers from the same nest were assigned to distinct clades. Second, two clades contained both Myrmica spinosior and M. scabrinodis. It looks like mitochondrial haplotypes are shuffled across populations and species. Deciphering species delineation in the Myrmica scabrinodis-group would probably require genomic data. COI sequences alone are most unlikely to enable the deciphering of the taxonomy of Myrmica and its Corsican populations. At this stage we consider it is safer to rely only on morphological features for exploring the diversity of Myrmica on this island.

Aphaenogaster spinosa forms a well-supported, monophyletic clade in which continental and island samples are intermixed. Genetic differentiation of COI among populations is strong. For instance, the average $k 2 p$ genetic distance within Corsica is higher than the usual cut-off threshold between species. Surprisingly high intraspecific genetic differentiation may be particularly common in Myrmicinae species, as noted by Schär et al. (2020). Regarding Aphaenogaster spinosa, this pattern is most likely due to colony multiplication by budding (new queens mate at the parental nest and disperse on foot), which restricts the flow of maternally inherited genes (such as mitochondrial genes). Phylogenetic inference does not support any of the proposed varieties or species that we investigated: neither the variety nitida nor the taxon Aphaenogaster corsica form a well-supported monophyletic clade. Information from COI markers supports previously established synonymies and is consistent with the mode of colony multiplication known in this species.

Although the ant fauna of Corsica is relatively well known, taxonomic changes occur regularly. We provide interested readers with an updated checklist of the ants of Corsica as supplementary material (Table S2), which is a compilation of the most recent information on the ant diversity on the island.

In conclusion, in seven of the eight cases studied, the $\sim 600$ bp COI barcode proved useful in determining the robustness of the morphology-based taxonomic decisions on the specificity of Corsican populations of different species of ants. Although we acknowledge that the COI sequence should not be the only source of information for taxonomic decisions, it constitutes a valuable, additional, clue when interpreted in the light of biological, ecological and morphological information. Ideally, delimitation of closely re- lated species should consider population genetics, or even, population genomics. However, such approaches are expensive and time-consuming, and as such, not available to many taxonomists. Sequencing COI is fast (efficient universal primers available) and relatively cheap and is a good compromise between state-of-the-art molecular techniques and no molecular information at all.

ACKNOWLEDGEMENTS. We thank T. Noel (University of Montpellier) and the members of the Groupe Naturaliste de l'Université de Montpellier (GNUM) for their help in processing samples, $\mathrm{P}$. Hebert (University of Guelph) for providing privileged access to the iBOL sequencing facility and M.-P. Dubois for providing facilities for molecular biology bench work. Two anonymous reviewers made suggestions that substantially improved this article. Data used in this work were partly produced using the GEMEX technical facilities of the Centre d'Ecologie Fonctionnelle et Evolutive with the support of LabEx CeMEB and an ANR Investissements d'avenir program (ANR-10-LABX-04-01). Many ant specimens were obtained through the AntArea project (www. antarea.fr). We thank P. Avoscan, E. Cade, T. Colin, L. Colindre, M. Fichaux, C. Foin, G. Ganem, P. Geniez, C. Lebas, A. Lerch, M. Roffet, A. Rotini, B. Schatz et P. Wegnez for collecting and providing samples of ants. This research was funded by grants from the Fond de Solidarité et de Développement des Initiatives Etudiantes (FSDIE) of the University of Montpellier and from the Office de l'Environnement de la Corse (OEC).

\section{REFERENCES}

Baroni Urbani C. 1971a: Studien zur Ameisenfauna Italiens XI. Die Ameisen des Toskanischen Archipels. Betrachtungen zur Herkunft der Inselfaunen. - Rev. Suisse Zool. 78: 1037-1067.

Baroni Urbani C. 1971b: Catalogo delle specie di Formicidae d'Italia (Studi sulla mirmecofauna d'Italia X). - Mem. Soc. Entomol. Ital. 50: 5-287.

BARTON N.H. 1996: Natural selection and random genetic drift as causes of evolution on islands. - Phil. Trans. R. Soc. Lond. (B) 351: 785-795.

Blatrix R., Wegnez P., Colin T. \& Galkowski C. 2017: Neuf nouvelles espèces de fourmis pour la Corse (Hymenoptera, Formicidae). - Rev. Assoc. Roussill. Entomol. 26: 60-64.

Blatrix R., Colindre L., Wegnez P., Galkowski C. \& Colin T. 2018: Atlas des Fourmis de Corse. Office de l'Environnement de la Corse, Corte, 147 pp.

BoER P. 2013: Revision of the European ants of the Aphaenogaster testaceopilosa-group (Hymenoptera: Formicidae). Tijdschr. Entomol. 156: 57-93.

Bondroit J. 1918: Les fourmis de France et de Belgique. - Ann. Soc. Entomol. Fr. 87: 1-174.

BondRoIT J. 1920: Notes diverses sur des fourmis d'Europe. Ann. Soc. Entomol. Belg. 59: 143-158.

Casevitz-Weulersse J. 1990: Etude systématique de la myrmécofaune corse (Hymenoptera, Formicidae) (Deuxième partie). - Bull. Mus. Natl. Hist. Nat. 12: 415-442.

COLINDRE L. \& GALKowsKi C. 2019: Strongylognathus huberi Forel 1874, nouvelle espèce de la faune corse (Hymenoptera, Formicidae). - Bull. Soc. Linn. Provence 70: 41-43.

Collingwood C.A. 1978: A provisional list of Iberian Formicidae with a key to the worker caste (Hym. Aculeata). - EOS 52: 65-95.

Csosz S., Heinze J. \& Mikó I. 2015: Taxonomic synopsis of the Ponto-Mediterranean ants of Temnothorax nylanderi speciesgroup. — PLoS ONE 10: e0140000, 62 pp. 
DAYRAT B. 2005: Towards integrative taxonomy. - Biol. J. Linn. Soc. 85: 407-415.

Ebsen J.R., Boomsma J.J. \& Nash D.R. 2019: Phylogeography and cryptic speciation in the Myrmica scabrinodis Nylander, 1846 species complex (Hymenoptera: Formicidae), and their conservation implications. - Insect Conserv. Divers. 12: 467480.

EDGAR R.C. 2004: MUSCLE: multiple sequence alignment with high accuracy and high throughput. - Nucl. Acids Res. 32: 1792-1797.

Galkowski C. \& Cagniant H. 2017: Contribution à la connaissance des fourmis du groupe angustulus dans le genre Temnothorax (Hymenoptera, Formicidae). - Rev. Assoc. Roussill. Entomol. 26: 180-191.

Grill A., Casula P., Lecis R. \& Menken S. 2007: Endemism in Sardinia. In Weiss S. \& Ferrand N. (eds): Phylogeography of Southern European Refugia. Springer, Dordrecht, pp. 273-296.

Hebert P.D. \& Gregory T.R. 2005: The promise of DNA barcoding for taxonomy. - Syst. Biol. 54: 852-859.

Hebert P.D.N., Penton E.H., Burns J.M., Janzen D.H. \& HallWachs W. 2004: Ten species in one: DNA barcoding reveals cryptic species in the neotropical skipper butterfly $A s$ traptes fulgerator. - Proc. Natl. Acad. Sci. U.S.A. 101: 14812-14817.

Jansen G., Savolainen R. \& Vepsalainen K. 2010: Phylogeny, divergence-time estimation, biogeography and social parasitehost relationships of the Holarctic ant genus Myrmica (Hymenoptera: Formicidae). — Mol. Phylogenet. Evol. 56: 294-304.

Lanfear R., Frandsen P.B., Wright A.M., Senfeld T. \& Calcott B. 2016: PartitionFinder 2: new methods for selecting partitioned models of evolution for molecular and morphological phylogenetic analyses. - Mol. Biol. Evol. 34: 772-773.

Maddison W.P. \& Maddison D.R. 2017: Mesquite: A Modular System for Evolutionary Analysis. V. 3.31. URL: http://www. mesquiteproject.org.

Maruyama M., Steiner F.M., Stauffer C., Akino T., Crozier R.H. \& SCHLICK-STEINER B.C. 2008: A DNA and morphology based phylogenetic framework of the ant genus Lasius with hypotheses for the evolution of social parasitism and fungiculture. - BMC Evol. Biol. 8: 237, 15 pp.

Medail F. \& Quezel P. 1997: Hot-spots analysis for conservation of plant biodiversity in the Mediterranean Basin. - Ann. Missouri Bot. Gard. 84: 112-127.
Myers N., Mittermeier R.A., Mittermeier C.G., Da Fonseca G.A. \& Kent J. 2000: Biodiversity hotspots for conservation priorities. - Nature 403: 853-858.

Plateaux L. \& Cagniant H. 2012: Quelques synonymies dans le genre Temnothorax Mayr, 1855 (Hymenoptera, Formicidae). Bull. Soc. Entomol. Fr. 117: 427-440.

RAdCHENKo A.G. 2016: Ants (Hymenoptera, Formicidae) of Ukraine. National Academy of Science of Ukraine, Schmalhausen Institute of Zoology, Kiev, 496 pp.

Radchenko A.G. \& Elmes G.W. 2010: Myrmica Ants (Hymenoptera: Formicidae) of the Old World. Natura Optima Dux Foundation, Warszawa, $789 \mathrm{pp}$.

Ronquist F., Teslenko M., van der Mark P., Ayres D.L., Darling A., Hohna S., Larget B., Liu L., Suchard M.A. \& HuelsenBECK J.P. 2012: MrBayes 3.2: efficient Bayesian phylogenetic inference and model choice across a large model space. - Syst. Biol. 61: 539-542.

Schär S., Menchetti M., Schifani E., Hinojosa J.C., Platania L., DAPPORTO L. \& VILA R. 2020: Integrative biodiversity inventory of ants from a Sicilian archipelago reveals high diversity on young volcanic islands (Hymenoptera: Formicidae). - Org. Divers. Evol. 20: 405-416.

Seifert B. 2020: A taxonomic revision of the Palaearctic members of the subgenus Lasius s. str. (Hymenoptera, Formicidae). — Soil Org. 92: 15-86.

Seifert B. \& Galkowski C. 2016: The Westpalaearctic Lasius paralienus complex (Hymenoptera: Formicidae) contains three species. - Zootaxa 4132: 44-58.

TalaVera G., Espadaler X. \& Vila R. 2015: Discovered just before extinction? The first endemic ant from the Balearic Islands (Lasius balearicus sp. nov.) is endangered by climate change. - J. Biogeogr. 42: 589-601.

WiLl K.W., Mishler B.D. \& WheELer Q.D. 2005: The perils of DNA barcoding and the need for integrative taxonomy. - Syst. Biol. 54: 844-851.

Received March 31, 2020; revised and accepted September 23, 2020 Published online October 29, 2020

Supplementary material:

Fig. S1 (see the following page).

Table S1 (http://www.eje.cz/2020/046/S01.xlsx). List of the samples used for phylogenetic reconstruction. Information includes collection details and GenBank accession numbers.

Table S2 (http://www.eje.cz/2020/046/S02.xlsx). Checklist of the ant species of Corsica. 
(a)
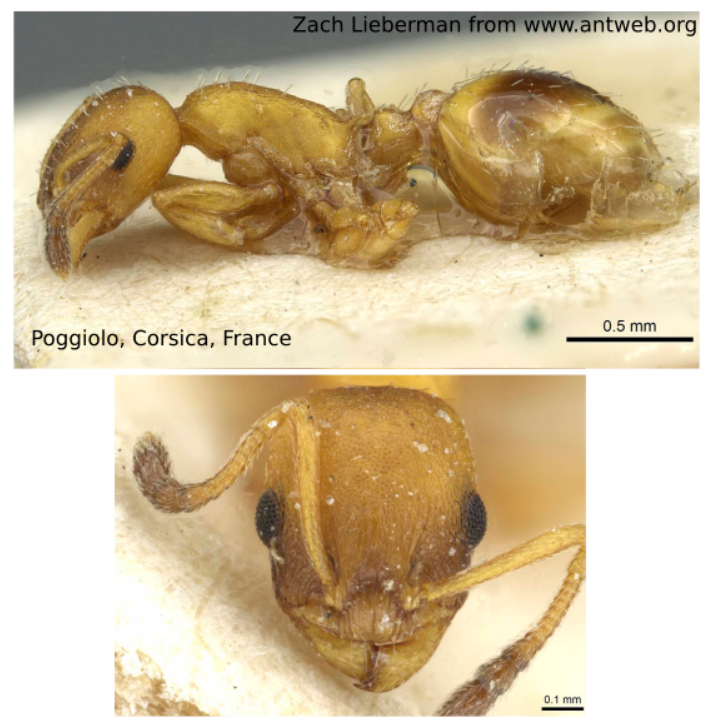

(c)
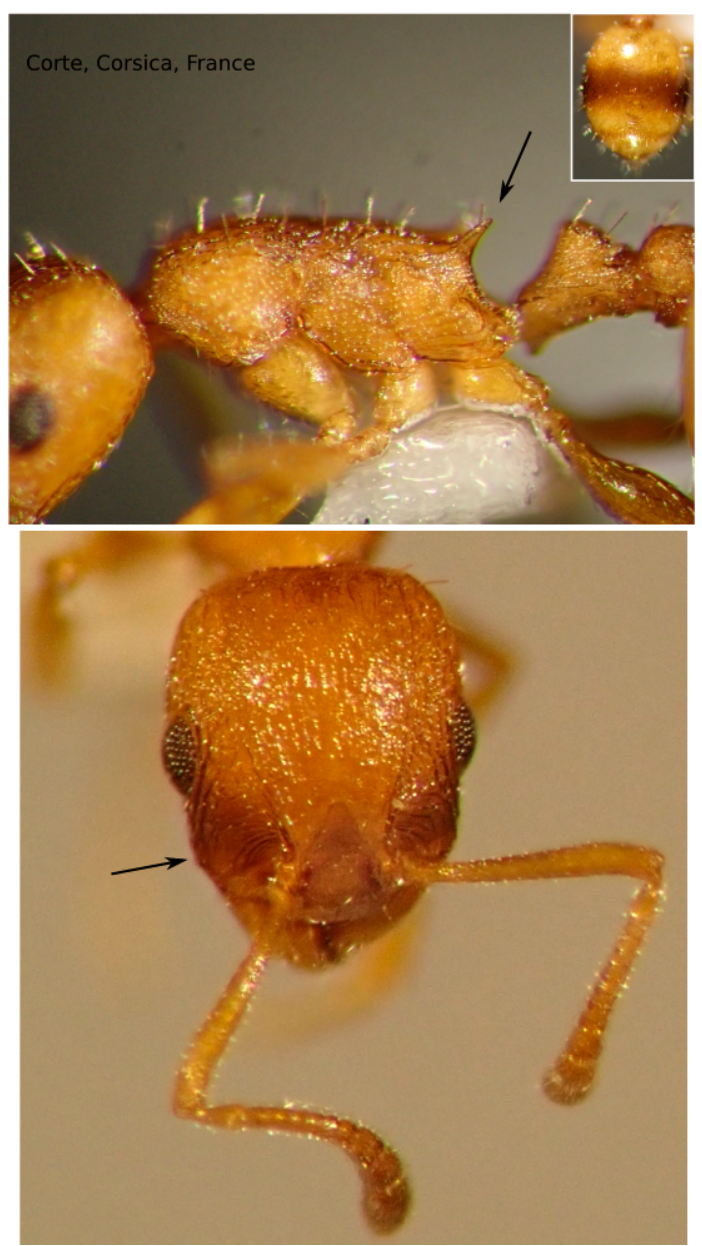

\section{Temnothorax unifasciatus}

(b)

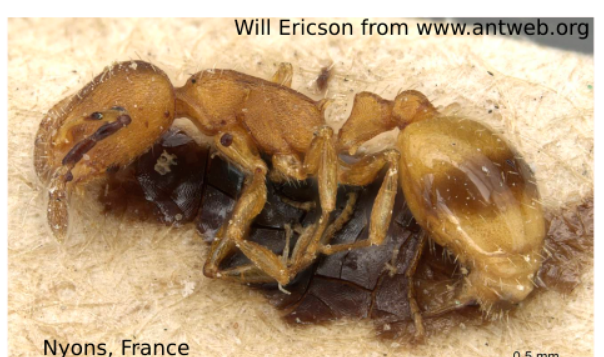

Nyons, France

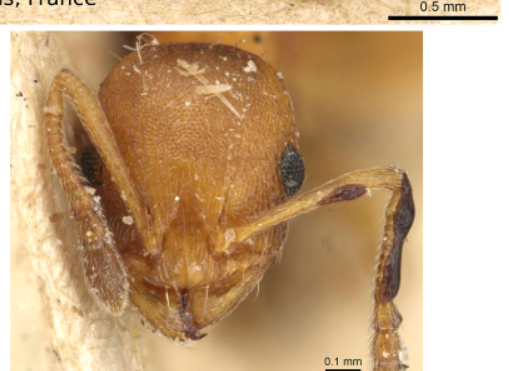

(d)
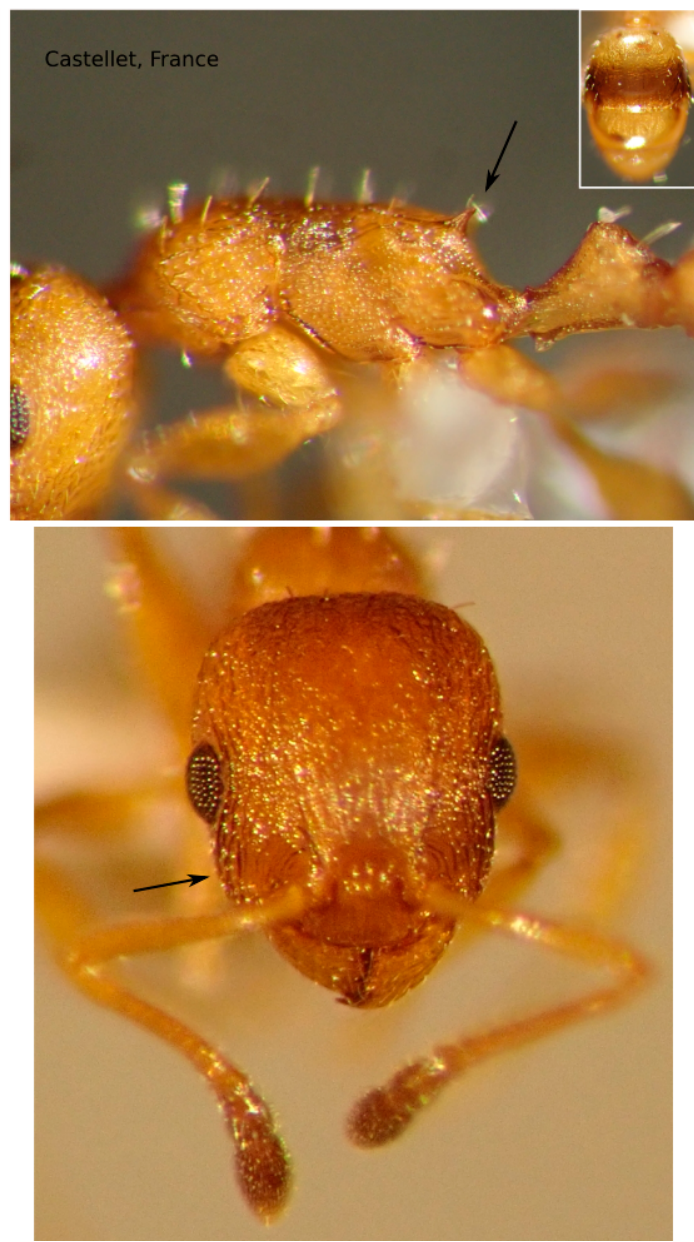

Fig. S1. Morphological comparison between Temnothorax unifasciatus (continent) and Temnothorax cordieri (Corsica). (a) AntWeb (www. antweb.org) pictures of the type of Leptothorax tuberum unifasciatus paolii Santschi, 1923 unavailable (CASENT0913011), = Temnothorax cordieri. (b) AntWeb (www.antweb.org) pictures of Temnothorax unifasciatus (CASENT0915379), from Nyons, France. We choose to illustrate this specimen because on AntWeb it is the nearest geographically to the type locality of Temnothorax unifasciatus. (c) and (d): pictures of our own specimens of Temnothorax cordieri and Temnothorax unifasciatus respectively, showing worker mesosoma with longer propodeal spines and worker head with darker genae in Temnothorax cordieri (left) than in Temnothorax unifasciatus (right) (see arrows). Inserts illustrate gaster from above, showing no obvious difference between the two species. 